\title{
EDUCATIONAL
} TECHNOLOGY

\section{Individual differences and technology attributes: An examination of educational technology considerations related to trade and industry training}

\author{
Mavis Bird \\ Richmond College of TAFE \\ Gerald Gill \\ Moorabbin College of TAFE
}

\begin{abstract}
This paper focuses on one of the major components of educational technology - instructional design. The paper deals with an examination of aspects of technology and learning which may have implications for future directions and developments in educational technology. It describes a study which examined the relationship between training technologies (computer and print) and individual learner differences (visual and haptic cognitive styles), in assisting learners' retention of information presented visually.
\end{abstract}

Three preliminary concerns formed the basis of this investigation. Firstly, the conduct of instructional design research in the area of industrial and trade training has been relatively limited. The current focusing of government and educational policy on that area would seem to suggest the need for research to increase the effectiveness of instructional design and educational technology related to these fields. Secondly, the facilities offered by computerisation and the move towards the rapid expansion of computer-based training has somewhat overshadowed the value of the more traditional and perhaps less dynamic technologies such as print. Now appears to be the appropriate time for instructional design to look beyond the superficial hardware and software capabilities of computer technologies -or what the computer can do -and examine more closely some of the fundamental learning issues related to computerisation and the presentation of instructional information. Finally, the growing trend towards the employment of visual information is producing and 
increasing awareness of the need for research concerning individual's acquisition of information from visuals.

The following research report is an example of the possible directions for research into such considerations.

\section{Characteristics of industrial and trade training}

Although cognitive requirements of tasks in trade and industrial training parallel those in the more general academic tertiary courses (eg. arts degree courses), the constraints imposed by the direct work or job related application of acquired skills creates a slightly different learning environment to the more traditional secondary or tertiary classroom environment. The structure of apprenticeship training courses, the specialised nature of each course, the close links between trainer, trainee and employer and the contextual constraints of the learning tasks (ie. the job specification) accentuate the restrictions of time and money or economics and efficiency considerations for task accomplishment. Further, the motivation of the learner (ie. the undertaking of a particular apprenticeship), the attitude of the learner (ie. specific purpose of the learning in the form of a trade qualification) and the aptitudes and abilities he/she brings to the learning situation play key roles in task accomplishment. The nature of trade training has for a long time been objective based, with perhaps greater emphasis being placed on individualised learning, mastery learning and systems-based modular training design formats than in any other branch of tertiary education in Australia. With regard to the unique aspects of this situation it is crucial that research into the design of instruction should serve to identify factors which will promote the effectiveness of the instruction.

\section{Technology in industrial and trade training}

Traditionally a large percentage of industrial and trade training has been based on the printed word. Instructional manuals, containing diagrams and pictures, but dependent primarily on printed text, originally formed the mainstay of industrial training materials. More recently, with moves towards more individualised instructional modes, and the consequent increased concern for individual learner differences, self-paced instructional manuals and training materials have been developed to meet the changing needs of training and industry. 
Currently, computerisation is being seen to more radically change the direction and nature of industrial and trade training. Within the context of this training, print- based materials are being supplemented by, used in conjunction with and, in many cases, superseded by computer-based training. The attributes of both computerisation and print-based materials have much to offer instruction and learning and examination of the relationship of their attributes to the learner and task may only serve to increase the quality of instruction through utilisation of more appropriate attributes and technologies.

\section{Visual information and trade training}

Within industrial and trade training apprentices are often required to conduct mental transformations of visual information, based on visual image retention. For example, apprentices are often involved with tasks such as those requiring the translation of measurements into plans, elevations and development from isometric or pictorial drawings. A number of learners have difficulties with such translations. One reason suggested for these difficulties is the learner's possible inability to retain the visual image. This inability may be related to the learner's cognitive style or an individual's manner of information processing.

\section{Information processing and visual information}

The construct of cognitive style is a research dimension which facilitates examination of individual learner differences which may be related to learning and the consequent design of instruction. Kogan (1971) describes cognitive style as the process by which knowledge is acquired. The concept defines an individual's approach to the processing of information and includes perception, memory, thinking and imagery.

Cognitive style may be defined as individual variations in modes of perceiving remembering and thinking, or as distinctive ways of apprehending, storing, transforming and utilising information. (Kogan, 1971, p275)

According to Messick (1976) an individual's cognitive style is a consistent pattern of organising and processing information with the emphasis being placed on the structure rather than the content of thought. In other words, cognitive style might be described as being concerned with how an individual obtains information and stores it (the internal processes) rather than with what the information or content is about. Ausburn and Ausburn (1978) have further described cognitive style as being relatively stable over time and across tasks, certain styles having been found to be largely 
resistant to change and training. Heidt (1978) emphasises the factor of individual preference and Winn (1982) elaborates on this notion, commenting that although the learner may have the appropriate information processing aptitudes, there is no guarantee that they will utilise them.

In summary then, examination of individual learner differences in terms of cognitive style might be said to generate the following considerations for instructional design:

- individuals differ in their cognitive style, and therefore in the ways in which they acquire information;

- cognitive style is concerned with the structure of thought, emphasising the manner in which information is acquired rather than the content;

- cognitive styles are predominantly stable, and can be resistant to change;

- whilst the learner may possess the appropriate ability they may not utilise it.

Eleven dimensions of cognitive style have been discussed in the literature (eg. Ausburn and Ausburn, 1978; Kogan, 1971) with some having been supported by a larger body of research than others. One dimension which appears to relate directly to the acquisition and retention of information from visuals is the Visual-Haptic dimension, first described by Lowenfeld in 1945.

\section{The visual-haptic dimension of cognitive style}

Lowenfeld (1945) differentiated between individuals:

whose tendency is to use their eyes as the main intermediaries for their
sense impressions and those who, though with normal sight, do not use
their eyes, but are more concerned with those perceptions that derive from
haptical experience. An extreme haptical type of individual - by no means
rare - is a normal sighted person who uses his eyes only when he is
compelled to do so; otherwise he reacts as would a blind person who is
entirely dependent upon touch and kinesthesis. (Lowenfeld, 1954, p101)

This definition implies that learners with more haptic tendencies may have greater need of assistance in instructional materials which require retention of visual information.

Several studies have utilised the dimension of visual-haptic in relation to instructional design research and visual information. Ausburn (1975) examined the use of supplantation on a comparative visual location task. The comparison was between a line image presentation and a multiple 
imagery presentation. His findings indicated that the multiple imagery presentation assisted both visual and haptic learners. In a more recent replication study the findings of Whitely and Moore (1979) confirmed those of Ausburn (1975). The present study utilised the perceptual type of visual-haptic in relation to the presentation modes of print based information and computer generated information.

The following paragraphs describe the methodology and materials used in the conduct of the study.

\section{Method}

The participants in the study were a group of eighty-four male apprentices attending trade courses in Panel Beating and Sheetmetal at two Victorian TAFE Training Colleges. All participants ranged in age from sixteen years to twenty-one years.

In order to obtain a measure of visual-haptic cognitive style each participant was administered a battery of three tests. These tests were repetitions of, or the equivalent of those used originally used by Lowenfeld.

\section{Test 1: Visualisation of kinesthetic experience}

This test was designed to examine the extent to which an individual visualised a kinesthetic experience. Figure 1 shows a sample test for visualisation of a kinesthetic experience. Briefly, five different geometric shapes of increasing complexity were etched individually, onto $3 \mathrm{~mm}$ aluminium plates. On cards each shape was drawn to scale accompanied by four similar shapes. Each plate was placed under a cover and the subject's hands explored the covered etching while he tried to visualise its shape, which was perceived kinesthetically. After feeling the shape and removing his hands from under the cover, the subject was asked to identify the etched shape from the five different shapes on the card.

\section{Test 2: Haptic word association test}

The second test administered to subjects was Lowenfeld's Visual-Haptic Word Association Test. This test was composed of twenty words, each of which elicits visual or haptic responses equally. The subject was given a list of words and asked to react to each word with the first association which came to mind. Scoring was conducted according to the procedures put forward by Lowenfeld. 


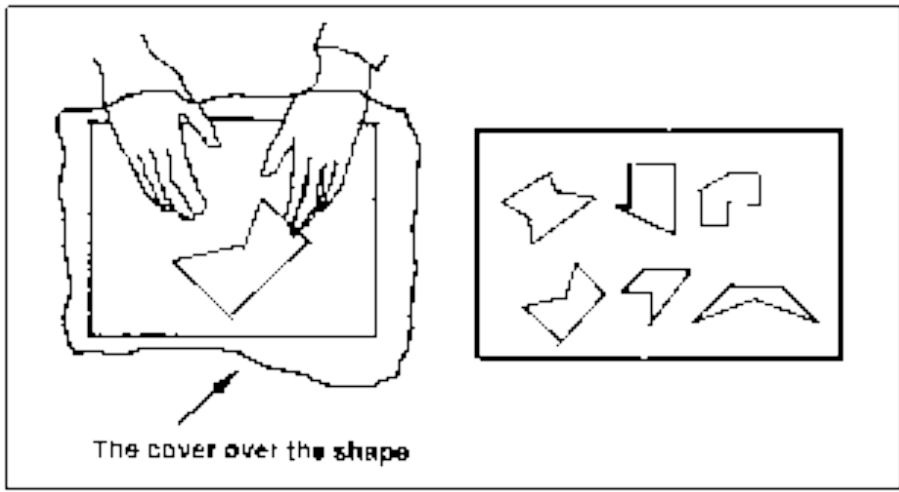

Figure 1: Examples from the test of Kinesthetic Experience

\section{Test 3: Test of subjective impressions}

This third test was an adaptation of Lowenfeld's test. The test was a simple drawing task in which the subject was shown and asked to draw his version of a stainless steel bowl resting on a table. A visual response to this test was to use a perspective form of representation (version A) - three dimensional, a haptic response being defined as a more two dimensional representation (version B) (Figure 2).

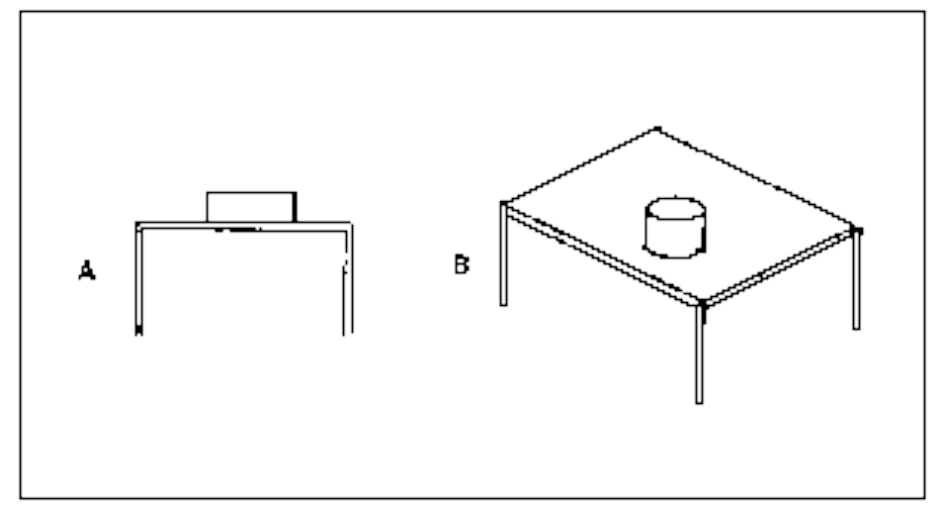

Figure 2: Examples from the test of Subjective Impressions 
Subjects were individually administered all three tests of perceptual type. Subjects were classified as visual if they gave visual responses to all three tests and haptic if they gave haptic responses on all three tests. The remaining subjects were classified as indeterminate and were excluded from the analyses. The results of these tests revealed that the obtained distribution of perceptual types was not significantly different from the approximate theoretical distribution posited by Lowenfeld. From each of the two extreme groups twelve subjects were assigned to one of two treatments (print based instruction or computer based instruction).

\section{Training and test materials}

Based on course content related to industrial safety and similar to the content used by Sellman (1972) the instructional and test materials dealt with the subject of fire containment. The performance measure was a task which required subjects to identify one of five classes of fire, the different types of fire and the relationship between the type of fire and the type of extinguisher to be used.

The print group received materials presented in print format. Subjects in this group were permitted to reread the instructions as often as they wished during the training period and to note responses in writing. Subjects in the computer based group interacted with the instructional materials via the terminal screen and keyboard. In this treatment only sequences not correctly answered in initial training attempts could be reviewed, the reviewing continuing until the correct response was obtained. Immediately following all training sessions subjects were presented with a post-test. Following a five-week interval subjects were retested on a delayed retention test.

\section{Results}

Data was analysed using analysis of variance. Examination of the means and standard deviations of visual and haptic subjects in both the immediate and delayed retention test revealed that whilst haptic subjects achieved a higher response score on the immediate retention test, visual subjects retained information better over a longer period of time (Figure $3)$. Of the two groups, haptic subjects performed best on the immediate test under conditions of print- based materials, whilst the reverse was true of haptics on the delayed retention test, those trained via computer-based training achieving a higher score. Visual subjects given training via 
computer performed better than those given print materials in the immediate post-test but the reverse was again found for this group on the delayed retention test, with subjects in the print group achieving a higher score than their counterparts in the computer-based training group.

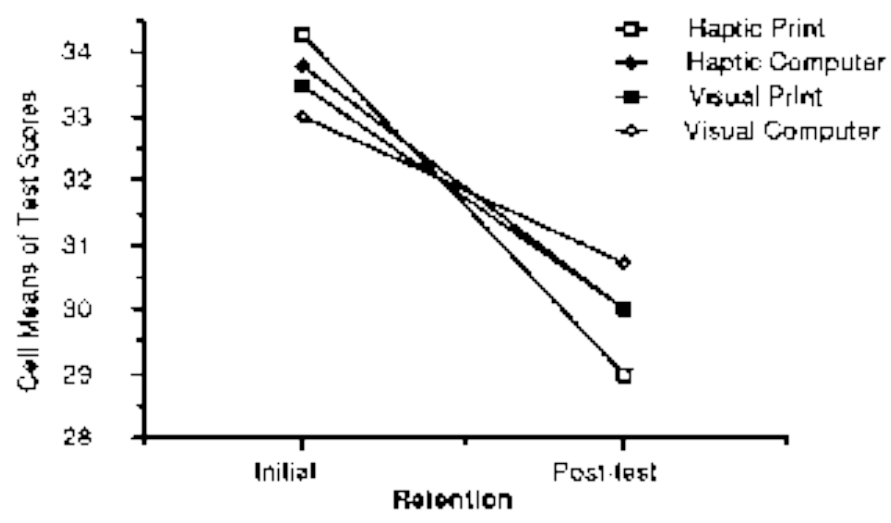

Figure 3: Graph of cell means for initial and retention tests

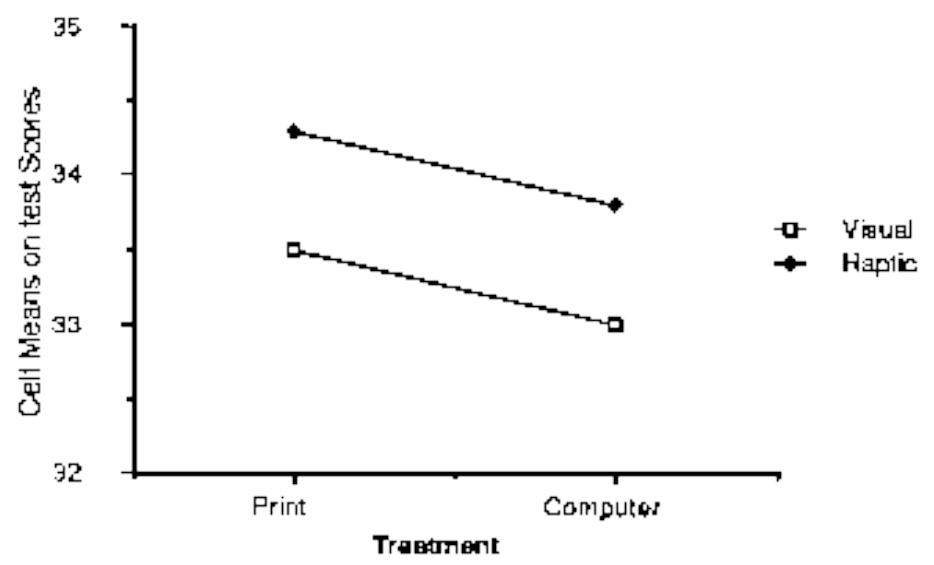

Figure 4: Test by Group intermediate retention scores 
In the initial post-test both visual and haptic subjects in the print treatment group had a higher mean response score than did their counterparts in the computer-based treatment group, however in the delayed retention test this trend was reversed (Figures 4 and 5). Both groups showed an expected drop in retention in the delayed retention test (Figure 4). In the analysis of variance no main effects nor interaction effects were found for any of the major variables in the study, although the results of these analyses indicated a trend towards significant differences in the performance of visual and haptic subjects under both conditions of presentation.

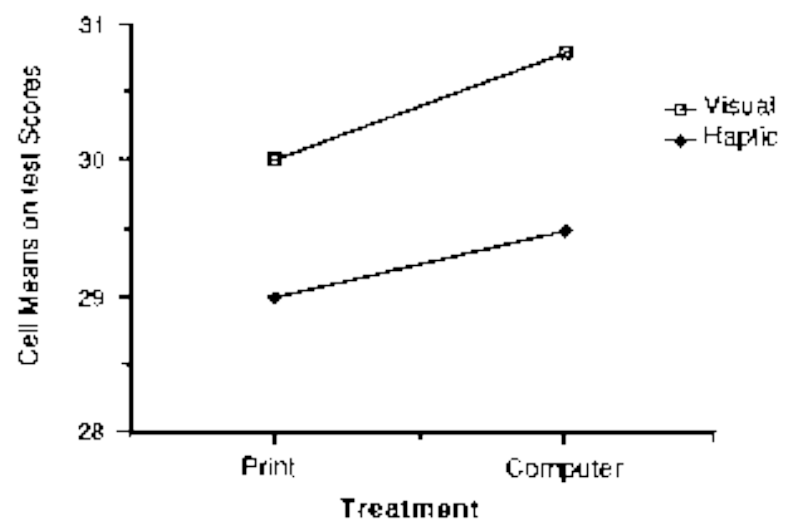

Figure 5: Test by Group delayed retention scores

\section{Conclusion}

The lack of significant differences between groups in this study may be attributed to the small number of subjects participating in the study. Further the algorithmic design of the computer generated materials used in the study may have failed to successfully tap the attributes of the computer to the extent that they did not adequately reflect the design of the print-based materials. For example the differences in review mechanisms between the groups (ie. print-based subjects having access to complete review, whilst computer-based subjects could only review incorrect sequences) may have influenced the results of the study. Despite the limitations of the study however, several considerations for instructional design and the use of computer and print based materials can be derived from the study. 
1. The performance of visual and haptic learners is likely to differ on visual identification tasks.

2. Both visual and haptic learners are likely to perform differently on immediate and delayed retention tests.

3. The differences between the groups (visuals and haptics) on the immediate and delayed retention tests indicates that the presentation mode must be taken into account when determining the required retention duration of the learning.

4. Retention duration of learning should be considered in the design of materials for individual learning styles.

In summary, the results of this study indicate that the design of instructional materials to suit individual needs may benefit from much greater consideration of differences in individual learning styles and the attributes offered by the different technologies. Much greater examination is required of computer based training and the attributes of the computer which lend themselves to this, as well as examination of the attributes of print-based instructional materials if the true values of the technologies for education and learning is to be realised.

\section{References}

Ausburn, F. B. (1978). Multiple versus linear imagery in the presentation of a comparative visual location task to visual and haptic college students. Unpublished Doctoral Dissertation, Oklahoma University: Oklahoma.

Ausburn, L. J. and Ausburn, F. B. (1978). Cognitive style: Some information and implications for instructional design. Educational Communications and Technology Journal, 26(4), 337-354.

Heidt, E. U. (1978). Instructional Media and the Individual Learner - A Classification and Systems Approach. London: Kogan Page.

Kogan, N. (1971). Educational Implications of Cognitive Style. In G. S. Lesser (Ed.), Psychology and Educational Practice. Glenview, Ill: Scott Foresman and Co, pp.242-292.

Lowenfeld, V. (1945). Tests for visual and haptical aptitudes. American Journal of Psychology, 58, 100-112.

Messick, S. (1976). Personality consistencies in cognition and creativity. In S. Messick and Assocs (Eds.), Individuality in Learning: Implications of Cognitive Style and Creativity for Human Development. San Francisco: Jossey Bass. 
Sellman, W. (1972). Reducing the literacy demands of training materials as one means of increasing learning in low-ability personnel. Journal of Experimental Education, 41(2), 54-59.

Whitely, J. B. and Moore, D. M. (1979). Effects of perceptual type and presentation mode in a visual location task. Educational Communications and Technology Journal, 27(1), 23-45.

Winn, W. (1982). Visualization in learning an instruction: A cognitive approach. Educational Communications and Technology Journal, 30(1), 325.

Please cite as: Bird, M. and Gill, G. (1987). Individual differences and technology attributes: An examination of educational technology considerations related to trade and industry training. Australian Journal of Educational Technology, 3(2), 108-118.

http: / / www.ascilite.org.au/ajet/ajet3/bird.html 